\title{
A CIDADANIA E A ÉTICA COMO EIXOS NORTEADORES DA FORMACÃO DO ENFERMEIRO
}

Roseney Bellato* Maria Aparecida Munhoz Gaíva**

\section{Resumo}

A partir de nossa vivência como docentes de Enfermagem buscamos com a presente reflexão alimentar a discussão sobre a formação profissional do enfermeiro tendo por eixos norteadores a Ética, os Direitos Humanos e a Cidadania. Entendemos a saúde como valor humano agregador de outros valores, sendo que os desafios com que nos deparamos nessa área não são da ordem dos conflitos morais, da escolha entre o bem e o mal, mas sim dilemas éticos, resultante da pluralidade de imperativos contraditórios que se colocam em jogo nesse cenário. Faz-se necessário, portanto, promover a formação de profissionais enfermeiros competentes para refletirem criticamente sobre as interrogações fundamentais que se apresentam na sua prática quotidiana, atuando de maneira ética e cidadã. Descritores: Ética; Cidadania; Ensino de enfermagem

\begin{abstract}
Based on our experience as Nursing Professors, we wish, by means of this reflection, to urge a discussion on nursing professional training, following guidelines as Ethics, Human Rights, and Citizenship. We understand health is a human value which elicits further values, and the challenges we face in this area are not of a moral kind, like choosing between good and evil - they are ethical dilemmas, stemming from the wide range of contradictory imperatives that are at stake within this scenario. It is paramount, therefore, to promote the professional training of competent nurses so that they can think critically about fundamental issues arising in their daily practice, and act according to ethics and citizenship values.

Descriptors: Ethics; Citizenship; Nurse teaching

Title: Citizenship and ethics as guidelines in nurse education
\end{abstract}

\section{Resumen}

A partir de nuestra experiencia como docentes de Enfermería buscamos con esta reflexión alimentar la discusión sobre la formación profesional del enfermero al presentar la Ética, los Derechos Humanos y la Ciudadanía como nortes de esa formación. Entendemos la salud como un valor humano que añade otros valores y los desafíos con los que nos deparamos en este campo no son del orden de los conflictos morales, de la elección entre el bien y el mal, pero sí dilemas éticos que resultan de la pluralidad de imperativos contradictorios que se ponen en juego en ese escenario. Por lo tanto, hay que promover la formación de profesionales enfermeros competentes, quienes ponderarán críticamente sobre las interrogantes fundamentales de su práctica cotidiana, para actuar de forma ética y con ciudadanía.

Descriptores: Ética; Ciudadanía; Enseñanza en enfermería

Título: La ciudadanía y la ética como nortes de la formación del enfermero

\section{Introdução}

Os problemas com que nos deparamos atualmente são tão complexos que não temos soluções para muitos deles. Esse dilema é particularmente verdadeiro na área da saúde, visto que esta se torna a confluência das muitas facetas do existir humano, e cujo maior desafio é contribuir na redução das desigualdades e na promoção da cidadania.

O reordenamento econômico, o avanço tecnológico, as transformações do mundo do trabalho levam a uma necessária e urgente mudança no perfil e nas relações do trabalho e do trabalhador. Essa mudança, atrelada diretamente à formação inicial desse trabalhador, mas que não se restringe apenas a ela, exige uma nova Educação que seja mais geral, versátil, crítica e permanente, de maneira a trazer respostas viáveis e eficazes aos muitos desafios que se apresentam na complexa teia do viver humano.

Precisa ser, portanto, preocupação urgente das instituições formadoras dos futuros profissionais essa discussão e a busca por soluções possíveis, quase sempre incertas e transitórias, visto que as transformações por que passa a sociedade são céleres no tempo, se pautando mais em arranjos e rearranjos do que em certezas pré-determinadas, duradouras e universais.

Entendemos que em nenhuma outra área da atividade humana tais preocupações se apresentam de maneira tão intensa como na área da saúde, visto que para ela confluem fatores condicionantes da ordem do político, do econômico, do social, do cultural, entre outros, cuja inter-relação produz um imaginário poderoso que, por sua vez, determina uma realidade multifacetada que precisa ser entendida na sua complexidade. Portanto, a discussão da temática cidadania e ética como eixos norteadores da formação dos profissionais da saúde, e particularmente do enfermeiro, se mostra bastante oportuna.

A busca por soluções para os muitos dilemas enfrentados na área da saúde necessita de um esforço coletivo dos profissionais que aí atuam, sendo que a enfermagem pode oferecer uma contribuição importante, razão pela qual nos propusemos a abordar a responsabilidade dos profissionais da saúde de uma maneira ampla, enfatizando a participação do enfermeiro nesse processo.

O objetivo deste trabalho é, pois, contribuir para a discussão sobre a formação profissional na área da saúde e, com especial acento, do enfermeiro, tendo a cidadania e a Ética como princípios fundamentais. Para tanto, faremos uma reflexão a partir de nossa vivencia como docentes de um Curso de Graduação em Enfermagem, atuando em disciplinas que têm como eixos norteadores as questões éticas da profissão, os Direitos Humanos, a Bioética, o direito a saúde e a cidadania.

\section{A saúde e a ética da vida}

Os tempos atuais trouxeram maravilhas tecnológicas que apontam para possibilidades nunca antes cogitadas pelo

\footnotetext{
* Doutora em Enfermagem. Professora do Departamento Enfermagem Médico-Cirúrgica da Faculdade de Enfermagem e Nutrição da Universidade Federal de Mato Grosso. Membro do Grupo de Pesquisa Enfermagem, Saúde e Cidadania.

** Doutora em Enfermagem. Professora do Departamento Enfermagem Materno-Infantil da Faculdade de Enfermagem e Nutrição da Universidade Federal de Mato Grosso. Membro do Grupo de Pesquisa Argos.

Email do autor: roseney@zaz.com.br
} 
ser humano, entre elas, a viagem virtual pelo corpo humano, a possibilidade de impedir o aparecimento de doenças futuras ainda no período intra-útero, a escolha das características e do sexo do bebê, e a possibilidade de reproduzirmos seres humanos ou seus órgãos através da clonagem. Estamos tratando de uma área onde ficção e realidade parece não ter uma fronteira nítida, sendo que aquela se apresenta apenas como uma antecipação desta.

Mas, essa mesma área que nos transforma em deuses também nos mostra a nossa faceta mais humana: a do sofrimento e da morte. E é dessa possibilidade tão concreta que nós, frágeis deuses humanos, tentamos fugir implacavelmente, embora de maneira vã.

E é no centro desse imaginário que a área da saúde e os profissionais que aí atuam se colocam: a Saúde como bem maior a ser conquistado e os profissionais como aqueles que são responsáveis por tal conquista. Cria-se, a partir de então, uma realidade auto-engendradora, na qual os seres humanos, fragilizados pelo medo do sofrimento e da morte, entendem a saúde como bem maior de sua existência, relegando o cuidado, a manutenção e o resgate dela aos profissionais da área que, como resultado, entre outros fatores, de uma formação profissional míope e acrítica, expropriam qualquer poder e domínio que as pessoas possam ter sobre si mesmas nesse processo, transformando-as em objeto passivo de sua prática profissional, negando-Ihes a posição de sujeitos de suas próprias vidas.

Portanto, qualquer mudança qualitativa que se queira empreender na formação dos profissionais que atuam na área da saúde no sentido de serem promotores de sua própria cidadania e no estímulo à cidadania do outro deve, necessariamente, possibilitar a compreensão dessa dimensão mítico-imagética que a permeia e que confere poder àqueles que a dominam. Tal compreensão se inicia no desvelamento da saúde como valor humano agregador de outros valores. É ela que nos nivela a todos, seres humanos, por entendemo-la como valor máximo em nossa existência, sendo mesmo considerada sinônima de felicidade. É a partir de sua perspectiva que valoramos e valorizamos as demais dimensões de nossa vida, é sob sua forte emblemática que entregamo-nos, de corpo e alma, àqueles que têm o "dom" de mantê-la ou restituí-la, residindo aí o seu poder, visto que ela pode se tornar tanto um bem manipulável em mãos pouco escrupulosas, como uma força motriz direcionada para as transformações sociais tão necessárias em nossa sociedade.

Por seu incomensurável poder de agregar outros valores, a saúde se torna cenário privilegiado para o exercício da ética da vida, pois vivemos um tempo de contradições em que, se por um lado a técnica e as ciências produziram desenvolvimentos notáveis neste século, por outro nos deparamos com uma profunda crise ética. Crise derivada, em grande parte, da inversão de valores que coloca o ser humano em segundo plano em relação aos ideais políticos e econômicos e não como centro destes $^{(1)}$.

Mas não nos referimos aqui à ética normativa, formal, e sim a Ética da Vida, visto que a exigência de ética que se manifesta um pouco em toda parte neste momento está ligada a uma tomada de consciência do desgaste, e mesmo da dissolução das éticas tradicionais em uma sociedade fortemente individualizada, ou seja, uma sociedade na qual há muita autonomia e liberdade individual, sendo que, no entanto, os valores (e, acrescentamos, os direitos) são distribuídos de maneira absolutamente heterogênea ${ }^{(2)}$. É necessário, no entanto, definirmos a Ética não centrada unicamente na vida humana, mas pautada nos direitos do ser humano, nos direitos da vida e também nos direitos da natureza pelos quais somos responsáveis. Acrescenta que, frente ao desenvolvimento atual da ciência e, sobretudo da biologia, desenvolvimento a um só tempo cognitivo e manipulador, nos vemos obrigados a redefinir a noção de pessoa humana, noção essa que era extremamente clara até o momento(3).

Como conseqüência desse esgarçamento da noção de pessoa humana que se nos apresenta na atualidade, convivemos com a disjunção entre a idéia de viver enquanto seres humanos e de sobreviver biologicamente, não apenas pelas inúmeras possibilidades de ampliação dos limites da vida e adiamento da morte que a ciência oferece, mas, principalmente, frente à baixa qualidade de vida que nos definem mais como sobreviventes do que como viventes. Foge-nos a consciência de que a saúde está diretamente relacionada, não ao grau de medicalizaçãoa que as pessoas estão sujeitas, mas à sua qualidade de vida.

Dessa idéia deriva a afirmativa, que muitas evidências empíricas têm demonstrado, que o enfoque biomédico não é capaz de dar conta da complexidade dos problemas de saúde das populações, nem tampouco de propor novas formas de organização da sociedade para enfrentá-los. Já está bastante claro que o aumento do fluxo de recursos aos serviços de saúde para satisfazer a voraz incorporação e expansão de tecnologias independentemente dos argumentos epidemiológicos e avaliativos, causam pouco impacto sobre o estado atual de saúde da população( ${ }^{(4)}$. Tal concepção tem raízes fortemente implantadas na crença tão presente em nossa sociedade e, o que é mais grave, sendo alimentada e estimulada pelos profissionais da área, que a saúde é o análogo inverso da doença. Essa distorção é claramente visualizada ainda na formação desses profissionais, estando toda ela embasada no equívoco de tematizar a saúde atrvés do seu negativo - $\underline{a}$ doença, deslocando para esta toda a sua atenção, fazendonos crer na possibilidade (mágica!?) de eliminá-la da vida humana.

O cenário atual, com o recrudescimento de doenças crônicas, a emergência e reemergência de doenças endêmicas e epidêmicas, o alto índice de morte tendo por causa básica a violência, nos mostra que os problemas de saúde com que nos deparamos são resultado de uma complexa rede de fatores sociais, econômicos, políticos, ambientais, entre outros, tendo a pobreza e, seu corolário, as péssimas condições de vida, uma de suas causas básicas.

No entanto, apesar de todos os problemas e dificuldades que enfrentamos, existem de fato condições para se lutar pela modificação da atual realidade com que nos defrontamos, particularmente nos paises periféricos. A oportunidade de ter acesso a saúde e educação dignas, de envolvimento da sociedade civil é possível desde que nos organizemos como cidadãos $^{(5)}$

Apresenta-se, assim, um ponto crucial para a reflexão acerca da formação profissional na área da saúde e, particularmente do enfermeiro: entendermos a saúde como direito e como possibilidade de conquista da cidadania. Ou seja, a saúde é um direito de cidadania e um bem público e todo esforço - individual ou coletivo - no sentido de conquistala e/ou mantê-la deve ser considerado um exercício de cidadania. A saúde é uma condição para a paz e, ao mesmo tempo, uma conseqüência dela, sendo também o antídoto para toda e qualquer violência, seja ativa ou passiva, discriminação, exclusão, exploração, intolerância. Nessa perspectiva o cuidado com a saúde nos remete essencialmente à valorização da vida(6).

Frente a um cenário tão plural como é o da Saúde, pensar a formação de profissionais para atuarem nessa área só pode ser feito de maneira a considerar essa complexidade, sob risco de reduzirmos ao nível meramente técnico tal formação. Os traços principais da competência atual ultrapassam marcadamente a posição passiva e repetitiva de gente apenas treinada. Se assim é, o que precisamos formar são profissionais não apenas habilmente adestrados, mas profissionais-cidadãos, formados para o exercício da cidadania própria e do outro e implicado com suas ações ${ }^{(7)}$. 
Neste contexto, as tendências na educação/formação do enfermeiro têm buscado um modelo mais humanista e critico, em que o centro do assistir deixa de ser a técnica, que vem fundamentando o modelo biomédico, cedendo espaço para o cuidado humano, formando profissionais com visão critica da realidade, com competência para agir com autonomia, comprometidos com os clientes, comunidade e com seu trabalho.

Mas, quais dimensões/princípios precisam ser considerados e resgatados na formação desse profissionalcidadão?

A dimensão humana precisa ser (re)inserida no centro dessa formação, sendo parte essencial do contexto de onde nunca deveria ter estado ausente. Embora se apresente como paradoxal tal afirmação, faz-se necessário humanizar a área da saúde. Mas, não se trata da humanização-maquiagem que propõe soluções superficiais para os graves problemas da área da saúde, mas da humanização como princípio ético, em que a construção de uma prática humanizada se articule as políticas de saúde, ao modo pelo qual se concebe qualidade de vida, saúde e cidadania. Nesse sentido, o trabalho comprometido com a humanização só terá razão e sentido se, em sua existência, trouxer a marca da resistência a toda política de saúde que anule os direitos do cidadão, seja ele cuidador ou aquele que necessita de cuidados $^{(7)}$.

Faz-se necessário lembrar também da dimensão estética nessa complexa formação profissional, reforçando a noção de estética como sendo um fenômeno relacionado ao sentido da corporeidade humana, ou seja, como o ser humano decodifica a presença do outro, sendo o corpo não apenas o organismo, mas compreendido como o lugar do acontecimento e do aparecimento da subjetividade, a partir da qual se inicia o processo de singularização e do aparecimento do humano(7).

É necessário lembrar que a a construção de uma política cidadã para a área da saúde precisa enfatizar a invenção de um projeto social, interdisciplinar, que considere a saúde em toda a sua rede de condicionantes e não focalize apenas a doença. Deve promover também a simetria nas relações de poder entre instituições de saúde/profissionais e as pessoas que necessitam de cuidados, possibilitando a participação ativa e responsável destes nas decisões a serem tomadas sobre sua saúde, tanto no nível da sua promoção, da prevenção, como da sua recuperação e reabilitação. Porém, não se trata de gerar uma nova ciência da saúde, mas sim uma teoria (e entendemos que precisa ser uma prática profissional) que traduza as diferentes necessidades, as múltiplas potencialidades, tornando diferentes linguagens inteligíveis e permitindo aos sujeitos definirem seus problemas e buscarem soluções ${ }^{(4)}$.

Os profissionais da saúde, e incluímos aqui também o enfermeiro, vêm sendo formados, nas últimas décadas, com um enfoque fundamentado na doença, com uma estruturação ideológica de um saber determinado por uma objetividade tecnicista e com grande ênfase no aparato tecnológico, que desconsidera a subjetividade dos sujeitos sob seus cuidados. É preciso reconsiderar esse centramento da atividade profissional nos instrumentais técnicos e tecnológicos, dandoIhes seu valor devido como instrumentais do cuidado e não como foco principal deste.

É claro que não podemos desconsiderar a dimensão técnica e tecnológica presente na formação dos profissionais da saúde, diminuindo-Ihe a importância. No entanto, é necessário desmistifica-la, redefinindo sua real possibilidade, desfazendo-se a ilusão de que o aparato tecnológico disponível na área da saúde seria capaz de compensar os desgastes decorrentes da precarização das condições de vida de grande parte da população. O saber em saúde precisa ser considerado como uma ferramenta tecnológica e não como um fim em si mesmo, transformando-se em saber-fazer, em saberincorporado pelo profissional, porém que respeita o saber do outro, tanto de outros profissionais quanto da pessoa sob seus cuidados, incorporando-o nas práticas de saúde, valorizando-o como válido, útil e legítimo.

Mas, se o contexto da saúde traz no seu bojo tal complexidade, como entender as relações que se estabelecem entre os diversos profissionais que nele atuam?

Entendemos que seja necessário primeiramente, desconstruir o conceito de autonomia profissional como ele tem se apresentado até o momento, e que aponta para saberes e fazeres estanques, autodelimitados, o que produz uma antinomia absoluta entre dependência e independência

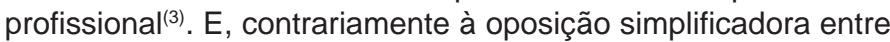
uma autonomia sem dependência e um determinismo de dependência sem autonomia, a nova noção de autonomia profissional só pode ser concebida em relação à idéia de dependência, ou seja, como resultante de sua própria complexidade o contexto da saúde gera dependências profissionais múltiplas, visto que a noção de autonomia é sempre relativa e relacional. Sendo assim, cabe-nos pensar emresponsabilidades profissionaisdiferenciadas, todas, no entanto, voltadas, em um esforço coletivo, para a preservação da vida e da saúde do ser humano.

\section{O ensino de enfermagem: princípios para uma atuação responsável, ética e autônoma}

O ensino da Ética na enfermagem durante muitas décadas foi pautado em um modelo predominantemente conservador, centrado em uma concepção normativa, com supervalorização de normas e códigos, ao invés de um ensino reflexivo-crítico, em que o exercício da enfermagem fosse considerado como uma pratica social historicamente construída no interior de uma área de atuação profissional condicionada pelas condições de vida dos seres humanos.

Mesmo que se reconheça que o ensino da Ética tenha caráter normativo, penso que é necessário que seja uma Ética aplicada, considerando as normas e os direitos, deveres e responsabilidades dos profissionais de enfermagem, contextualizados com o nosso cenário de saúde, as características de nosso país. O Brasil caracteriza-se por uma sociedade dividida, na qual as desigualdades sociais estão cada vez mais evidentes e acentuadas, levando um contingente cada vez maior da população a se situar abaixo da linha da pobreza. Assim, as conseqüências dessa situação desenham um perfil epidemiológico próprio. A formação do enfermeiro deve enfocar também os dilemas bioéticos atuais, que apontam para contradições marcantes no interior da área da saúde face aos avanços técnico-científicos de nosso tempo, capacitando-o para uma prática conseqüente que possibilite a proposição de soluções possíveis e realizáveis.

Em nossa experiência como docentes de um curso de Graduação em Enfermagem temos buscado envolver, de maneira gradativa, demais docentes e alunos na discussão tão necessária acerca do compromisso ético do profissional enfermeiro com a construção/promoção da cidadania dos sujeitos que se colocam sob seus cuidados. Os campos de prática se mostram ricos em situações concretas, tanto no que se refere a situações quotidianas como frente a situações limite ${ }^{(8)}$, que possibilitam a análise crítica dos direitos e responsabilidades profissionais frente ao Código de Ética, à Ética da Vida e os direitos dos usuários de serviços de saúde tendo por base as políticas públicas de saúde e a organização do trabalho em saúde e em enfermagem.

Por entendermos que a Ética é transversal a todas as disciplinas, uma das nossas grandes preocupações diz respeito à perspectiva de inseri-la como um enfoque interdisciplinar, contando com a participação de dirigentes de órgãos de classe e de defesa dos direitos dos usuários de serviços de saúde, bem como de enfermeiros inserido em diversas áreas de atuação profissional. Buscamos, assim, uma 
concepção pluralista que visa enfocar interrogações fundamentais presentes na nossa prática profissional quotidiana que, embora nem sempre sejam passíveis de resposta imediata, precisam ser articuladas em discussões aprofundadas possibilitando aos futuros profissionais o exercício da reflexão crítica para atuarem de maneira cidadã e ética.

\section{Considerações finais}

Está claro, portanto, que se trata de uma 'aventura' complexa (re)pensar a formação profissional na área da saúde e, em especial na enfermagem, exigindo um grande esforço a ser coletivamente empreendido para alcançarmos resultados ainda imprecisos a curto prazo. No entanto, é necessário ter em mente que a construção/reconstrução de Projetos Políticos Pedagógicos que possam dar sustentação e viabilidade as dimensões aqui apresentadas e que ultrapassam, em muito, a até então valorizadíssima dimensão biológica, se fará no próprio caminhar compartilhado dos docentes, alunos e enfermeiros atuantes nas diversas áreas profissionais. Pois entendemos que as contribuições para uma formação voltada a uma prática ética e cidadã se fazem presentes na medida em que os próprios profissionais de enfermagem, docentes ou não, lancem um novo olhar para seu fazer quotidiano, ou seja, procurem ser críticos para com suas próprias necessidades enquanto membros de uma profissão com características tão peculiares, ao mesmo tempo em que dialoguem com o sujeito de sua prática - a pessoa cuidada.

Consideramos, portanto, que para a construção de uma realidade profissional voltada para a cidadania, necessitamos propiciar aos alunos condições para desenvolvimento da competência humana que considera não apenas os aspectos técnico-instrumentais envolvidos na prática profissional, mas que se torna o pano de fundo onde se desdobram todas as demais competências, sendo necessário compreende-la como um conceito político-educacional abrangente, como um processo de articulação e mobilização gradual e contínua de conhecimentos gerais e específicos, de habilidades teóricas e práticas, de hábitos e atitudes e de valores éticos, que possibilite ao profissional o exercício eficiente de seu trabalho, a participação ativa, consciente e crítica no mundo do trabalho e na esfera social, além de sua efetiva auto-realização. Ou, em outras palavras, a competência humana se apresenta como um outro nome para a cidadania e, como esta, aponta para o processo emancipatório que significa o processo histórico de conquista da condição de sujeito coletivo e autônomo ${ }^{(9)}$.

\section{Referências}

1. Fiedler-Ferrara N. Ciência, ética e solidariedade. In: Carvalho EA, Almeida MC, Coelho NN, Fiedler-Ferrara N, Morin E. Ética, solidariedade e complexidade. São Paulo: Palas-Athena; 1998. 77 p. p. 29-47.

2. Morin E. Ética e imaginário. In: Pena-Veja A, Almeida CRS, Petraglia I, organizadores. Edgar Morin: ética, cultura e educação. São Paulo: Cortez; 2001. 175 p. p. 31-111.

3. Morin E. Ciência com consciência. Rio de Janeiro: Bertrand do Brasil; 1998. $344 \mathrm{p}$.

4. Serrano MM, Lemos S. Promoção da saúde: um novo paradigma? Boletim Abrasco, Rio de Janeiro 2002 mai/ago;85:5-9.

5. Greco D. Ética, saúde e pobreza: as doenças emergentes no século XXI. Bioética, Brasília (DF) 1997;5(2):41-8.

6. Associação Palas Athenas. Ética do acolhimento. Revista THOT, São Paulo 2002 maio;2:63-9.

7. Silva FV, Menezes MDGAS. Formação profissional e humanização dos serviços de saúde. Formação, Brasília (DF) 2002 maio;2(5):5974.

8. Berlinguer G. Questões de vida: ética, ciência e saúde. São Paulo: HUCITEC; 1993. $218 \mathrm{p}$.

9. Deluiz N. Qualificação, competências e certificação: visão do mundo do trabalho. Formação, Brasília (DF) 2001 maio;1(2):5-15.

Data de recebimento: 30/08/2003

Data de aprovação: 30/10/2003 